\title{
The effect of mechanical activation on synthesis and properties of $\mathrm{MgAl}_{2} \mathrm{O}_{4}$ ceramics
}

\author{
N. Obradovića,*, W.G. Fahrenholtz ${ }^{\mathrm{b}}$, S. Filipovića ${ }^{\mathrm{a}}$, D. Kosanovića ${ }^{\mathrm{a}}$, A. Dapčevićc, A. Đorđevićd,e, \\ I. Balaćf ${ }^{f}$ V.B. Pavlovića \\ ${ }^{a}$ Institute of Technical Sciences of the Serbian Academy of Sciences and Arts, 11000, Belgrade, Serbia \\ ${ }^{\mathrm{b}}$ Materials Science and Engineering, Missouri University of Science and Technology, Rolla, MO, United States \\ ${ }^{\mathrm{c}}$ Department of General and Inorganic Chemistry, Faculty of Technology and Metallurgy, University of Belgrade, 11120, Belgrade, Serbia \\ ${ }^{\mathrm{d}}$ School of Electrical Engineering, University of Belgrade, 11000, Belgrade, Serbia \\ ${ }^{\mathrm{e}}$ Serbian Academy of Sciences and Arts, 11000, Belgrade, Serbia \\ ${ }^{\mathrm{f}}$ Faculty of Mechanical Engineering, University of Belgrade, Belgrade, Serbia
}

\section{A R T I C L E I N F O}

\section{Keywords:}

Mechanical activation

Sintering

Microstructure

Electrical properties

Mechanical properties

Spinel

\begin{abstract}
A B S T R A C T
Magnesium aluminate, $\mathrm{MgAl}_{2} \mathrm{O}_{4}$ and other alumina-based spinels are ceramics with high hardness, high melting point and mechanical strenght. Spinels can also be used as dielectrics in microwave applications. The goal of this study was to examine the effects of mechanical activation and sintering temperatures on physico-chemical properties of spinel.

$\mathrm{MgAl}_{2} \mathrm{O}_{4}$ was produced by solid state reaction between $\mathrm{MgO}$ and $\alpha-\mathrm{Al}_{2} \mathrm{O}_{3}$. The starting powders were mixed by ball milling to homogenize without significant particle size reduction. Mechanical activation of mixed powders was performed in a high-energy planetary ball mill in air for $1 \mathrm{~h}$. Powders were compacted at $300 \mathrm{MPa}$. Heat treatments were performed in air, at temperatures ranging from 1200 to $1600{ }^{\circ} \mathrm{C}$ with $2 \mathrm{~h}$ dwell time, to determine the amount of spinel formation as a function of temperature. Phase composition and microstructure of initial powders and heated samples were determined by means of X-ray diffraction, particle size analysis, and scanning electron microscopy. The influences of milling and consolidation parameters were studied by electrical measurements and mechanical characterization.

The main conclusion of this study was that mechanical activation for $60 \mathrm{~min}$ initiated a mechano-chemical reaction, resulted in spinel formation at much lower temperatures than within non-activated powders, and indicated that final sintering stage started at much lower temperatures for activated powders. Changes in microstructure parameters, as a consequence of mechanical treatment and subsequent heating of investigated powder mixtures, strongly affect electrical and mechanical properties of the final ceramics.
\end{abstract}

\section{Introduction}

Magnesium aluminate, $\mathrm{MgAl}_{2} \mathrm{O}_{4}$, is a ceramic of great importance in modern technologies due to its properties, such as high hardness, high melting point and low dielectric constant. It can be used as a dielectric in microwave applications [1]. When fully dense, pure $\mathrm{MgAl}_{2} \mathrm{O}_{4}$ can be transparent. Owing to its high mechanical strength and low cost, spinel ceramics have been used extensively in various applications, e.g., as transparent armor, IR windows, and radomes [2,3].

The properties of ceramics strongly depend on the composition, nature of raw materials, impurities or additives, and fabrication methods [4]. Two main approaches have been used to obtain fully dense spinel ceramics. The first one is densifying by hot pressing, pressureless, spark plasma, and microwave sintering utilizing spinel powder as the raw material, with or without sintering aids [5-12]. The advantages of this approach include obtaining fully dense transparent ceramics with excellent electrical and mechanical properties. On the other hand, calcination to react precursors prior to sintering and/or heating for several hours at very high temperatures $\left(>1700^{\circ} \mathrm{C}\right)$ with or without a high pressure for densification are disadvantages in terms of energy consumption and control of microstructure. The second approach is reactive sintering, which usually uses oxides or hydroxides of magnesia and alumina as starting powders [13,14]. A homogeneous precursor is produced by wet chemical methods, like co-precipitation, sol-gel, etc. [15-17]. These methods are cheaper due to the reduced energy consumption, but are also more complicated and production of

\footnotetext{
${ }^{*}$ Corresponding author.

E-mail address: nina.obradovic@itn.sanu.ac.rs (N. Obradović).
} 
large quantities of powders is difficult.

Preparation conditions and consolidation parameters have a great impact on the final structure and properties of ceramic materials [18]. Solid-state reaction between $\mathrm{MgO}$ and $\alpha-\mathrm{Al}_{2} \mathrm{O}_{3}$ represents the common approach to produce spinel ceramics due to its simplicity, low cost, and ability to produce larger amounts of products that are necessary for detailed investigations or commercial production. Kinetic or diffusion limitations are common in solid-state reactions, but can be overcome by mechanochemical activation [19]. Mechanical activation is commonly used to enhance the reactivity of materials, reduce particle sizes, increase diffusion rates, and accelerate the reaction [20]. Mechanochemical treatments can lead to a significant increase in the concentration of structural defects. Attrition of the starting material, amorphization, and introduction of defects, phase transformations, and possible chemical reactions during the treatments typically decrease synthesis and densification temperatures. In addition, the time needed for chemical reactions can be shortened, which leads to energy savings [21]. Furthermore, mechanical activation can also affect the final electrical and mechanical characteristics, which provides motivation to explain changes that occur during high-energy ball milling [22]. Such milling processes are attractive method because they enable the formation of submicrometer and/or nanostructured materials with desirable properties [23].

There have been attempts to investigate the effect of mechanical activation on synthesis of $\mathrm{MgAl}_{2} \mathrm{O}_{4}$ ceramics, and influence of those parameters on densification, and physico-chemical properties of the final product, but not using $\mathrm{MgO}$ and $\alpha-\mathrm{Al}_{2} \mathrm{O}_{3}$ as precursors [24,25]. The objective of this work is to investigate the effects of the high-energy ball milling on phase composition, microstructure, electrical, and mechanical properties of sintered $\mathrm{MgAl}_{2} \mathrm{O}_{4}$ ceramics.

\section{Experimental procedure}

A mixture of high-purity $\mathrm{MgO}$ and $\alpha-\mathrm{Al}_{2} \mathrm{O}_{3}$ starting powders (all 99.9\% purity Sigma-Aldrich, p.a.) was used in these experiments. The starting $\mathrm{MgO}$ and $\alpha-\mathrm{Al}_{2} \mathrm{O}_{3}$ powders were added in a one-to-one molar ratio to produce stoichoimetric $\mathrm{MgAl}_{2} \mathrm{O}_{4}$. The powders were mixed by ball milling to homogenize them without significant particle size reduction. Part of the powder mixture was mechanically activated for $60 \mathrm{~min}$ in a high-energy planetary ball mill (Planetary Ball Mill Retsch PM 100) in air. Mechanical activation was performed by using Y-stabilized $\mathrm{ZrO}_{2}$ vials and balls. The media were $5 \mathrm{~mm}$ in diameter. The ball-to-powder weight ratio was 40:1 with a rotation speed of $400 \mathrm{rpm}$. Powders were sieved after milling. The powder mixtures were labeled based on the activation time as AM-0 (ball milled only) and AM-60 (ball milled plus $60 \mathrm{~min}$ mechanical activation). The binder-free powders were compacted at $300 \mathrm{MPa}$ using a uniaxial double action pressing process with an $8 \mathrm{~mm}$ diameter tool (hydraulic press RING, P14, VEB THURINGER). Compacts were placed in an alumina boat and heated in a tube furnace (Lenton Thermal Design Typ 1600). Conventional sintering was performed in air, at temperatures ranging from 1200 to $1600^{\circ} \mathrm{C}$ with heating rates of $10^{\circ} \mathrm{C} \cdot \mathrm{min}^{-1}$ and a $2 \mathrm{~h}$ dwell time. The bulk densities were calculated from measurements of mass, diameter, and thickness of the sintered specimens, according to equation:

$\rho=\frac{4 \cdot m}{D^{2} \cdot \pi \cdot h}$.

where $m$ is the mass of the sintered sample, $D$ is the diameter, and $h$ is the height. After sintering, the sintering temperatures were added to the specimen designations such that AM-60-1200 indicates a specimen that was produced from powder that was mechanically activated for $60 \mathrm{~min}$ and sintered at $1200^{\circ} \mathrm{C}$. The theoretical density (TD) of the mixtures was assumed to be $3.60 \mathrm{~g} \mathrm{~cm}^{-3}$ based on previous reports [26].

Average particle size and particle size distribution were determined by a laser light-scattering particle size analyzer (PSA; Mastersizer 2000, Malvern Instruments Ltd., UK), covering the particle size range of $0.02-2000 \mu \mathrm{m}$. For the PSA measurements, the powders were dispersed in distilled water in an ultrasonic bath (low-intensity ultrasound, at a frequency of $40 \mathrm{kHz}$ and power of $50 \mathrm{~W}$ ) for $5 \mathrm{~min}$.

The morphology of the powders and sintered specimens was analyzed by the scanning electron microscopy (JEOL JSM-6390 LV). Prior to SEM observations, the powders and crushed sintered samples were coated with gold to minimize charging. The phase composition of powders was identified based on x-ray diffraction (XRD) patterns obtained on a Philips PW-1050 diffractometer with $\mathrm{Cu}-\mathrm{Ka}$ radiation $(\lambda=1.5418 \AA)$ and a step/time scan mode of $0.05 \mathrm{~s}^{-1}$ in the $2 \theta$ range 15-90. The XRD patterns for pulverized sintered specimens were collected on an Ital Structure APD $2000 \mathrm{X}$-ray powder diffractometer using CuKa radiation $(\lambda=1.5418 \AA)$ in a range $2 \theta=\left(20-80^{\circ}\right)$ with a stepwidth of $0.02^{\circ}$ and a constant counting time of 1 s per step. The program PowderCell [27] was used for the determination of approximate phase contents using a Rietveld-like refinement process. The theoretical density of pulverized sintered samples was determined using equation (2):

$\rho=(M Z) /\left(V N_{\mathrm{A}}\right)$

where $M$ is the molar mass of $\mathrm{MgAl}_{2} \mathrm{O}_{4}, \mathrm{Z}$ is the number of chemical formula units per unit cell, $V$ is the volume of unit cell determined by XRD analysis, and $N_{\mathrm{A}}$, Avogadro's number. The unit cell was calculated from the lattice parameter, $a$, of the cubic spinel unit cell by $\mathrm{V}=a^{3}$, where $a$ was determined using a least-squares method with the LSUCRIPC program [28]. The relative dielectric permittivity (dielectric constant) and the loss tangent of the sintered specimens were measured in the frequency range between 10 and $500 \mathrm{MHz}$ using an Agilent E5061A network analyzer. The specimens were placed in a coaxial test chamber. The reflection coefficient of the chamber was measured by the analyzer and the relative complex permittivity of the specimens was extracted using an electrostatic model.

The strength of the sintered specimens was determined by diametral compression of sintered cylinders [29]. A revised formula (Equation (3)) for calculating the tensile strength that takes into account the thickness to diameter ratio of the cylinder was proposed by $\mathrm{Yu}$ et al. [30]. In this method, a relatively thin circular disc/cylinder is compressed diametrically until failure, which occurs due to tensile stresses that develop normal to direction of the applied compressive load. For valid tests, the tensile stresses are essentially constant across a region around the center of the specimen. The indirect tensile strength is typically calculated based on the assumption that the failure occurs at the point of maximum tensile stress, which is at the center of the disc:

$\sigma_{t}=(1+0.2621 k) \frac{2 P}{\pi D t}$

where $P$ is the load at failure, $D$ is the diameter of the test specimen, $t$ is the thickness of the test specimen measured at the center, and $k$ is the ratio of the thickness to the diameter ( $t / D)$ of the disc specimen [30]. For the tests conducted as part of the present study, the lower platen was fixed, while the upper was moveable and applied the load. The load was slowly increased until failure, which occurred when a vertical crack split the specimen into two parts. The applied force $(P)$ and the displacement $(\delta)$ were recorded until failure.

\section{Results and discussion}

The phase composition of the starting powders is presented in Fig. 1. All diffraction lines were identified using corresponding JCPDS cards (74-1081 for $\alpha-\mathrm{Al}_{2} \mathrm{O}_{3}, 45-0946$ for $\mathrm{MgO}$, and 33-0853 for $\mathrm{MgAl}_{2} \mathrm{O}_{4}$ ). A mixture of the starting oxides $\left(\alpha-\mathrm{Al}_{2} \mathrm{O}_{3}\right.$ and $\left.\mathrm{MgO}\right)$ was detected in the non-activated powder (AM-0). The sharp, intense peaks indicated the microcrystalline nature of the starting components.

The same phases were detected after $60 \mathrm{~min}$ of high-energy ball 


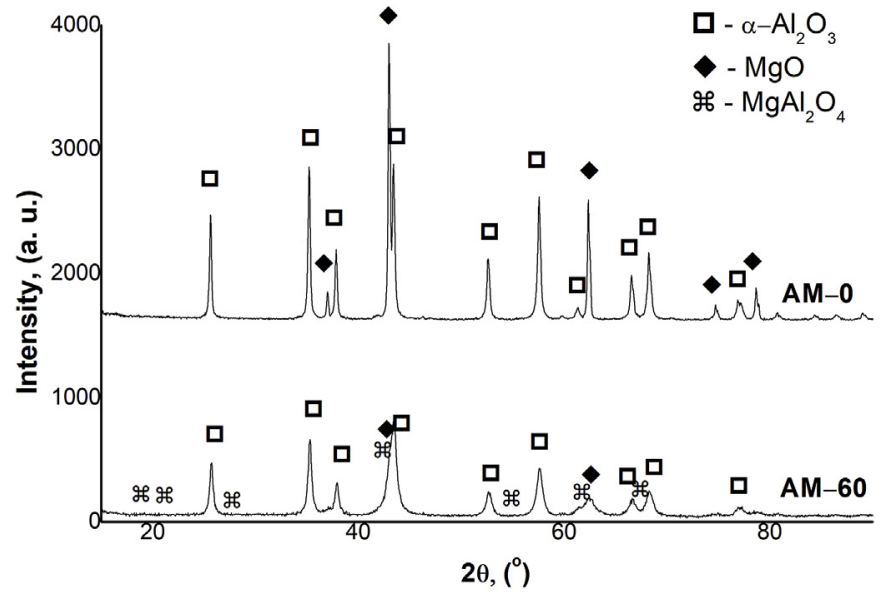

Fig. 1. XRD patterns of powders: non-activated powder (AM-0) and powder activated for $60 \mathrm{~min}$ (AM-60).

milling. However, the intensities of the peaks decreased and the peaks were broadened, which is characteristic of mechanically activated powders. Activation can result in amorphization and/or introduction of defects into the particles. The changes in the XRD patterns are consistent with reduction of the starting particle size and introduction of residual stresses or defects in the final particles.

Scanning electron micrographs and EDS maps are presented in Fig. 2. Non-activated powder consisted of two different types of powder particles. The first type was smaller, around $300 \mathrm{~nm}$ in diameter. These particles were typically present as agglomerates that were

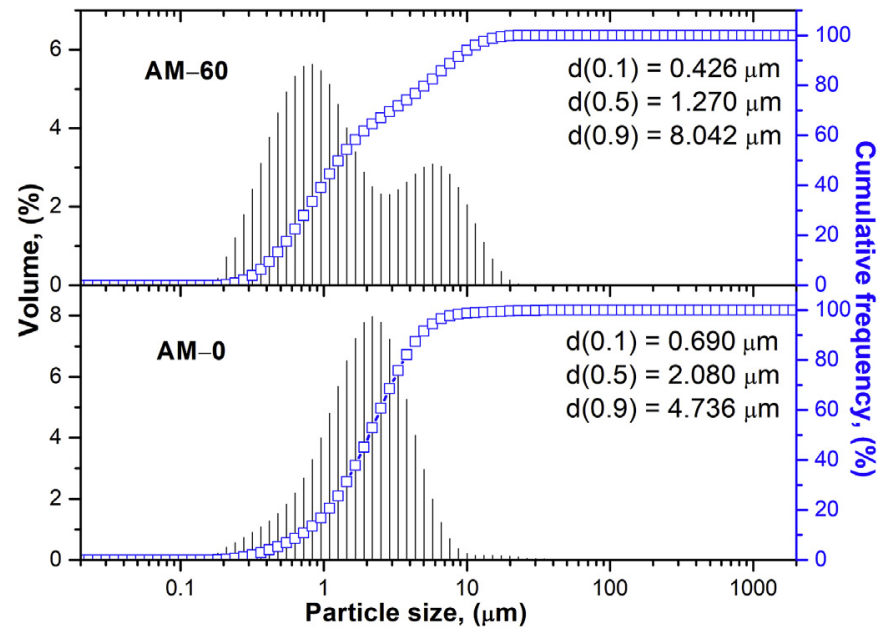

Fig. 3. PSA of the non-activated powder (AM-0) and powder activated for $60 \mathrm{~min}(\mathrm{AM}-60)$.

approximately $1 \mu \mathrm{m}$ in size. Energy dispersive spectroscopy indicated that these particles were rich in $\mathrm{Mg}$ and $\mathrm{O}$ and were likely the $\mathrm{MgO}$ starting particles. The second type of particles was larger, with polygonal shapes. These particles ranged in size from about $1.5 \mu \mathrm{m}$ to $2.5 \mu \mathrm{m}$ across. Analysis by EDS indicated that these particles were likely to be the starting $\alpha-\mathrm{Al}_{2} \mathrm{O}_{3}$ (see Fig. 3).

The powder activated $60 \mathrm{~min}$ appeared to be homogeneous with an obvious reduction in agglomerate size. The smaller particles were produced as the $\mathrm{MgO}$ agglomerates were comminuted. The larger
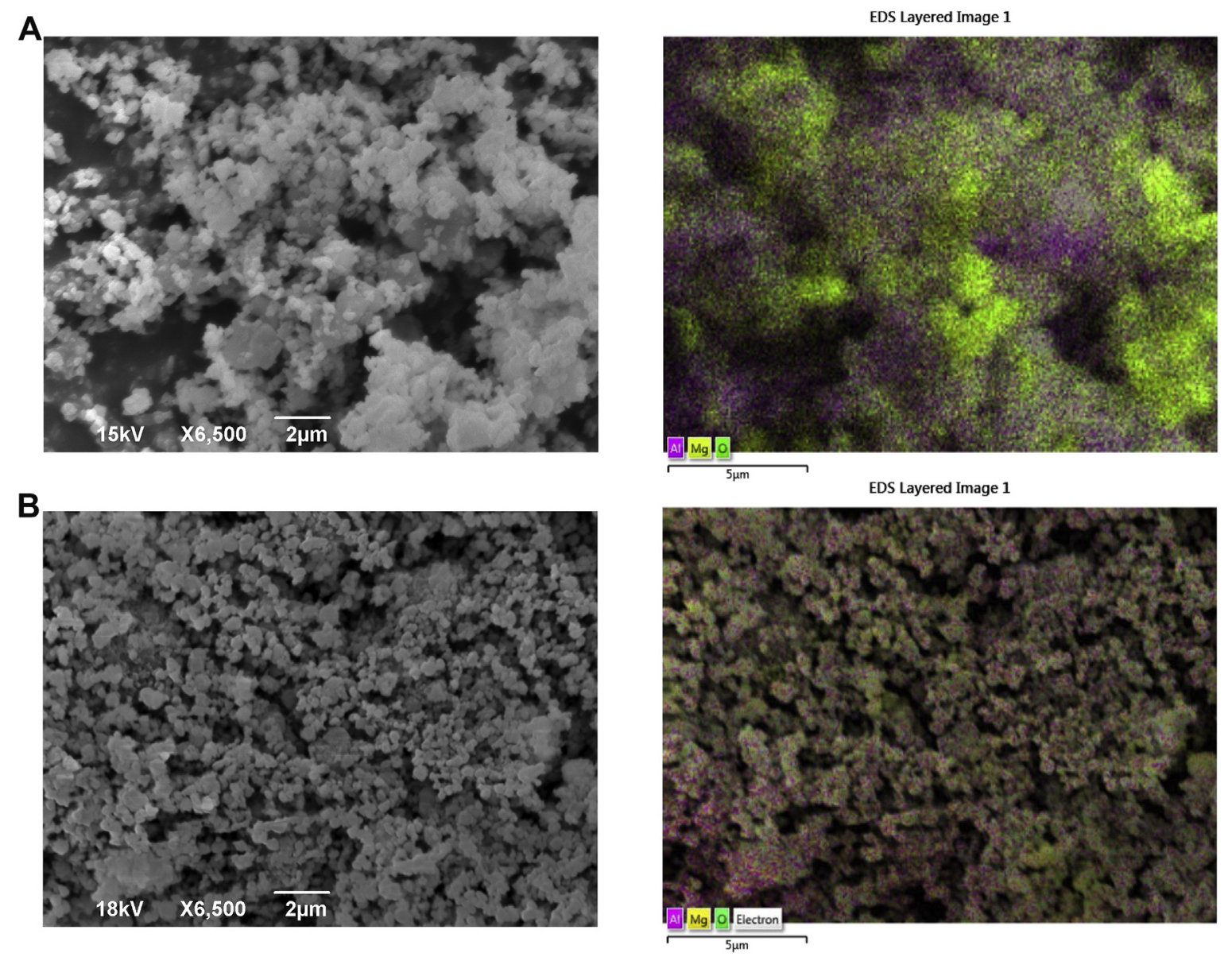

Fig. 2. SEM and EDS pictures of powders: a) non-activated powder (AM-0) and b) powder activated for 60 min (AM-60). 

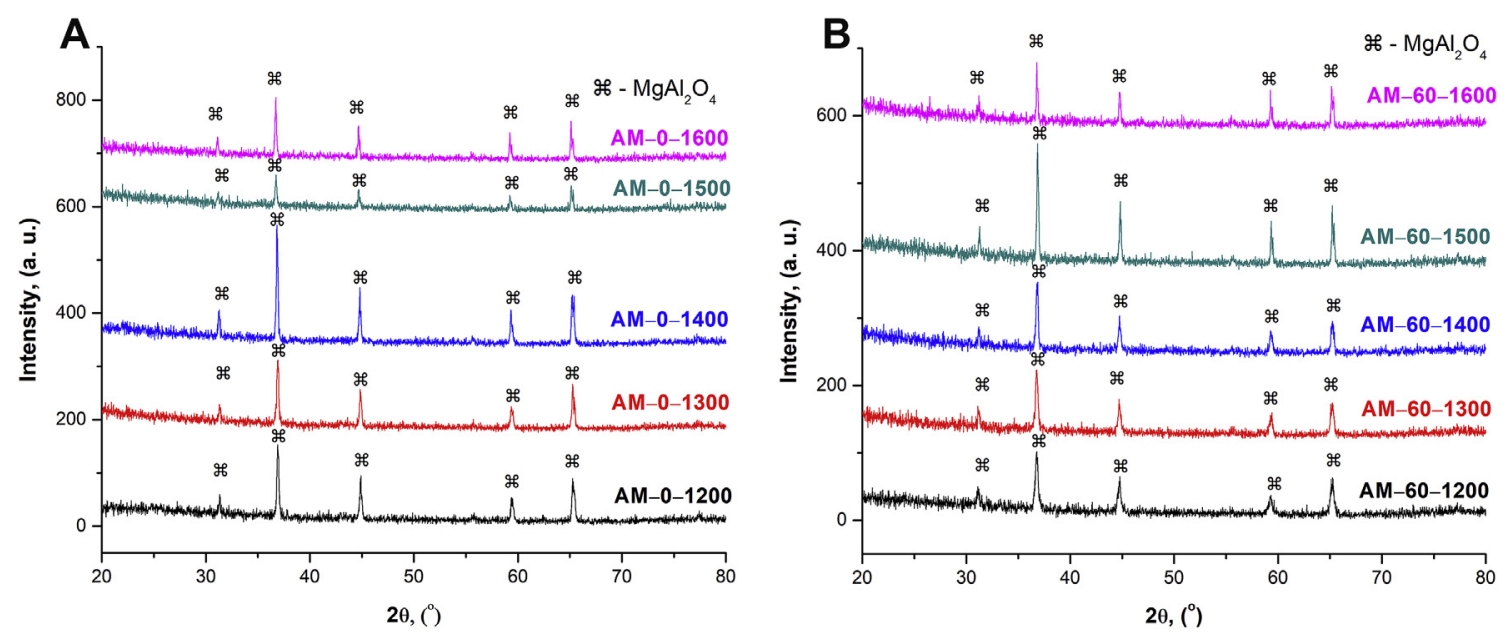

Fig. 4. XRD patterns of: a) non-activated powder (AM-0) and b) powder activated for 60 min (AM-60), after heating to various temperatures for $2 \mathrm{~h}$ in air.

alumina particles were also broken down into equiaxed particles that were $1 \mu \mathrm{m}$ or smaller in diameter. EDS analysis indicated a uniform distribution of $\mathrm{Al}$ and $\mathrm{Mg}$ species in the activated powder.

The results of the particle size analysis were consistent with the SEM analysis. The average particle size $d(0.5)$ was $2.1 \mu \mathrm{m}$ for the non-activated powder AM-0. After mechanical activation for $60 \mathrm{~min}$, the average particle size decreased to about $1.3 \mu \mathrm{m}$. Likewise $\mathrm{d}(0.1)$ decreased from $0.69 \mu \mathrm{m}$ for $\mathrm{AM}-0$ to $0.43 \mu \mathrm{m}$ for AM-60. Interestingly, $\mathrm{d}$ (0.9) increased from $4.74 \mu \mathrm{m}$ for AM-0 to $8.04 \mu \mathrm{m}$ for AM-60. Milling also produced a bimodal particle size distribution in the AM-60 powder with peaks in the distribution at about $0.8 \mu \mathrm{m}$ and $5 \mu \mathrm{m}$. While milling reduced the average particle size significantly, it also produced some agglomerates that were larger than in the starting powder.

The XRD patterns of heat treated powders are presented in Fig. 4. All reflections were identified using the corresponding JCPDS card 33-0853 for $\mathrm{MgAl}_{2} \mathrm{O}_{4}$. All peaks were sharp, indicating that the $\mathrm{MgO}$ and $\mathrm{Al}_{2} \mathrm{O}_{3}$ powders reacted to form the spinel phase of $\mathrm{MgAl}_{2} \mathrm{O}_{4}$. No peaks belonging to $\mathrm{MgO}$ and $\mathrm{Al}_{2} \mathrm{O}_{3}$ were apparent when the entire pattern was observed.

Also, no peaks were observed for $\mathrm{ZrO}_{2}$, which could have been introduced as contamination into the powder during mechanical activation that used zirconia vial and milling balls. More detailed analysis using Rietveld-like refinement revealed the existence of $\mathrm{MgO}$ phase after heating. For $\mathrm{AM}-0, \mathrm{MgO}$ contents ranging from 3.7 to $8.2 \mathrm{wt} \%$ were detected. For the activated powders, the $\mathrm{MgO}$ content decreased from $5.3 \mathrm{wt} \%$ in AM-60-1200 to $1.1 \mathrm{wt} \% \mathrm{MgO}$ in AM-60-1300. Heating to temperatures of $1400{ }^{\circ} \mathrm{C}$ or higher resulted in the formation of phase-pure spinel. In addition, the lattice parameters of the crystalline spinel powders were analyzed to calculate the theoretical density values based on the unit cell volumes. The calculated theoretical densities ranged from 3.55 to $3.59 \mathrm{~g} \mathrm{~cm}^{-3}$, which were in good agreement with accepted values for stoichiometric $\mathrm{MgAl}_{2} \mathrm{O}_{4}$.

Bulk density increased with increasing sintering temperature for all of the compositions (Fig. 5). The lowest values were obtained after sintering at 1200 and $1300{ }^{\circ} \mathrm{C}$ (around $51 \%$ TD), where almost no densification had occurred. At $1400^{\circ} \mathrm{C}$ and above, the bulk density values increased and reached over $92 \%$ TD after sintering at $1600^{\circ} \mathrm{C}$. Bulk densities were higher for activated samples, probably due enhanced sintering that resulted from the finer average particle size of the AM-60 powders after the mechanical treatment. Deviation from the general trend was observed at $1600{ }^{\circ} \mathrm{C}$.

Scanning electron micrographs of fracture surfaces of the sintered specimens produced from the non-activated powders (AM-0 series) are presented in Fig. 6 . The non-activated specimen sintered at $1200{ }^{\circ} \mathrm{C}$ for $2 \mathrm{~h}$ consisted of two regions. The first consisted of particles that did not react during sintering and particles with necks that formed during

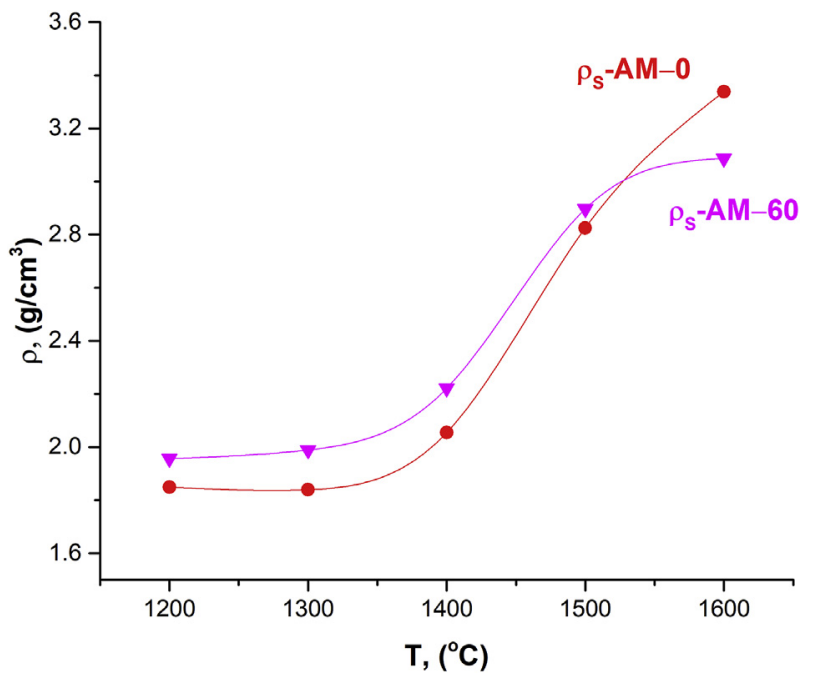

Fig. 5. Bulk density as a function of sintering temperature for all sintered samples.

sintering (see the left side of Fig. 6a). The second region (on the right side of Fig. 6a) possessed densified particles that had started to react. Specimen AM-0-1300 appeared to have a higher degree of sintering, but also some parts of the specimen that still appeared to consist of the initial powders. In addition to the non-uniform grain size, cracks were present, which were presumed to form around regions that corresponded to agglomerates in the initial powder compact.

After sintering at $1400{ }^{\circ} \mathrm{C}$, no regions that had the appearance of the unreacted powders were observed in AM-0-1400. Breakage between grains, irregular pores, and agglomerates were visible, which indicated that grain growth had not yet started and that this specimen remained in the intermediate stage of sintering. Spherical pores and breakage through grains observed for AM-0-1500 indicated that this specimen had entered the final sintering stage. Some breakage between smaller grains was observed, confirming that those grains were not fully developed. Non-uniform grain growth was observed in this sample, as well. When the sintering temperature was increased to $1600^{\circ} \mathrm{C}$, all of the grains were polygonal and all of the pores were spherical and closed. Based on appearance, AM-0-1600 had high relative density and appeared to be completely sintered, in agreement with measured densities (see Table 1).

Sintering of activated powders at temperatures of $1200{ }^{\circ} \mathrm{C}$ was sufficient to complete the reaction to form spinel and enter the initial sintering stage. Fig. 7a shows that AM-60-1200 consisted of sub- 
A

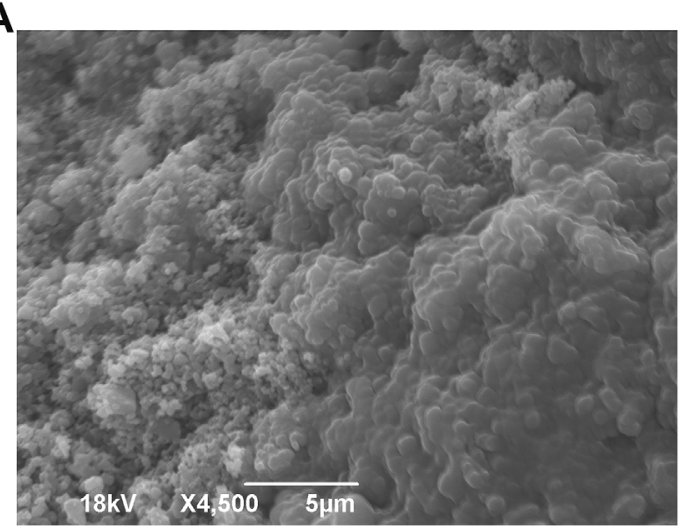

C

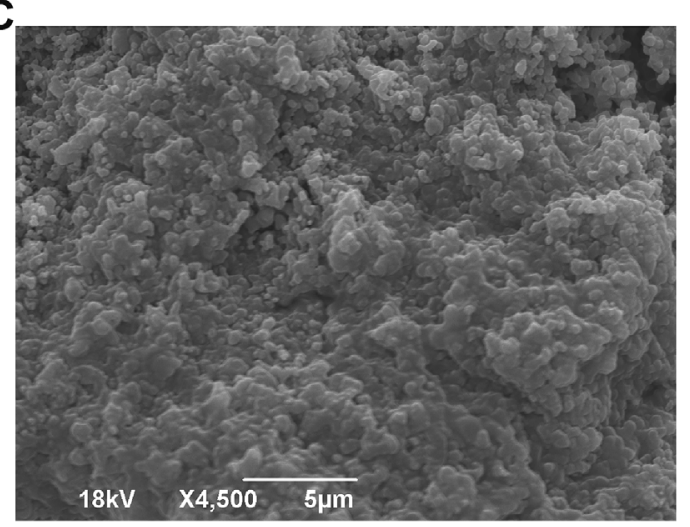

B

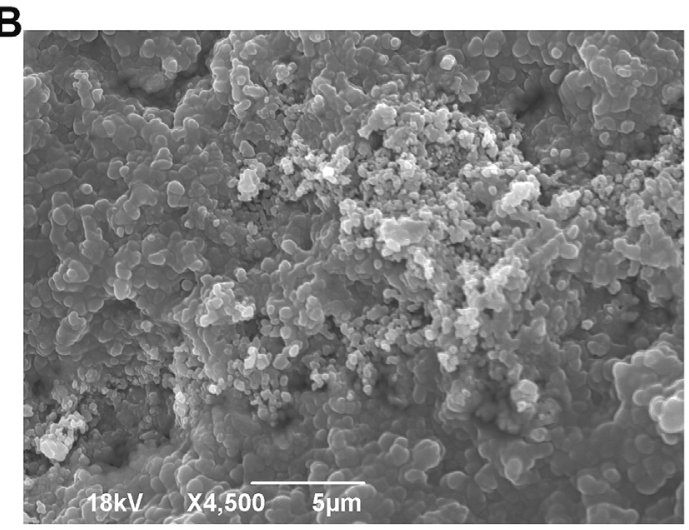

D

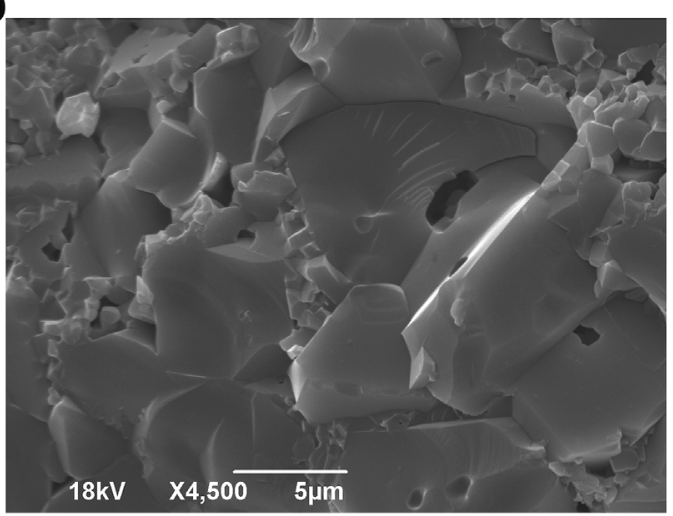

E

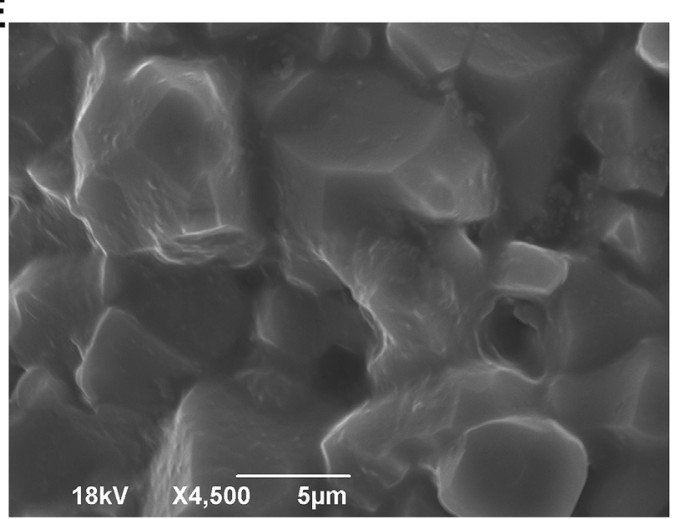

Fig. 6. SEM micrographs of fracture surfaces of specimens: a) AM-0-1200, b) AM-0-1300, c) AM-0-1400, d) AM-0-1500, and e) AM-0-1600.

Table 1

Dimensions and density parameters of sintered pellets.

\begin{tabular}{lllllll}
\hline Sample & $m_{\mathrm{s}}(\mathrm{g})$ & $t(\mathrm{~mm})$ & $D_{\mathrm{s}}(\mathrm{mm})$ & $\rho\left(\mathrm{g} \cdot \mathrm{cm}^{-3}\right)$ & $\rho_{\text {rel }}(\% \mathrm{TD})$ & $\Pi(\%)$ \\
\hline AM-0-1200 & 0.2053 & 1.92 & 8.58 & 1.85 & 51.4 & 48.6 \\
AM-60-1200 & 0.2064 & 1.95 & 8.30 & 1.96 & 54.3 & 45.7 \\
AM-0-1300 & 0.2005 & 1.89 & 8.57 & 1.84 & 51.1 & 48.9 \\
AM-60-1300 & 0.1950 & 1.87 & 8.17 & 1.99 & 55.3 & 44.7 \\
AM-0-1400 & 0.2068 & 1.91 & 8.17 & 2.05 & 57.1 & 42.9 \\
AM-60-1400 & 0.1939 & 1.78 & 7.92 & 2.22 & 61.7 & 38.3 \\
AM-0-1500 & 0.1988 & 1.70 & 7.26 & 2.83 & 78.5 & 21.5 \\
AM-60-1500 & 0.1980 & 1.66 & 7.24 & 2.90 & 80.5 & 19.5 \\
AM-0-1600 & 0.2047 & 1.58 & 7.03 & 3.34 & 92.7 & 7.3 \\
AM-60-1600 & 0.1924 & 1.61 & 7.02 & 3.09 & 85.8 & 14.2 \\
\hline
\end{tabular}

micron powder particles with fully open porosity. Contact necks had formed among all of the particles. While some agglomerated particles were observed, neck formation was also observed within agglomerates.

The AM-60-1300 specimen had regions that appeared to sinter to higher relative density than the surrounding regions. The majority of the specimen consisted of particles which had started to form necks. The presence of open porosity and non-uniform microstructural regions indicated that this specimen was still in the initial sintering stage. The main characteristics for AM-60-1400 were breakage through grains and uniform grain size with open porosity. By $1400{ }^{\circ} \mathrm{C}$, the pores were becoming more spheroidal and the dominant fracture mode was through grain. At this temperature, microstructures were almost completely compact. Non-uniform grain growth was observed in AM-60-1600. Compared to lower sintering temperatures, the amount of porosity was lower and additional polygonal grains had formed. Pores appeared to be closer together and were coalescing into closed pores, which is indicative of final stage sintering.

The relative dielectric permittivity as a function of sintering temperature followed the same trend as bulk density as shown in Fig. 8 [31]. The density increased with sintering temperature, which indicated that higher sintering temperatures led to lower porosity and more compact structures, which was also consistent with observed 

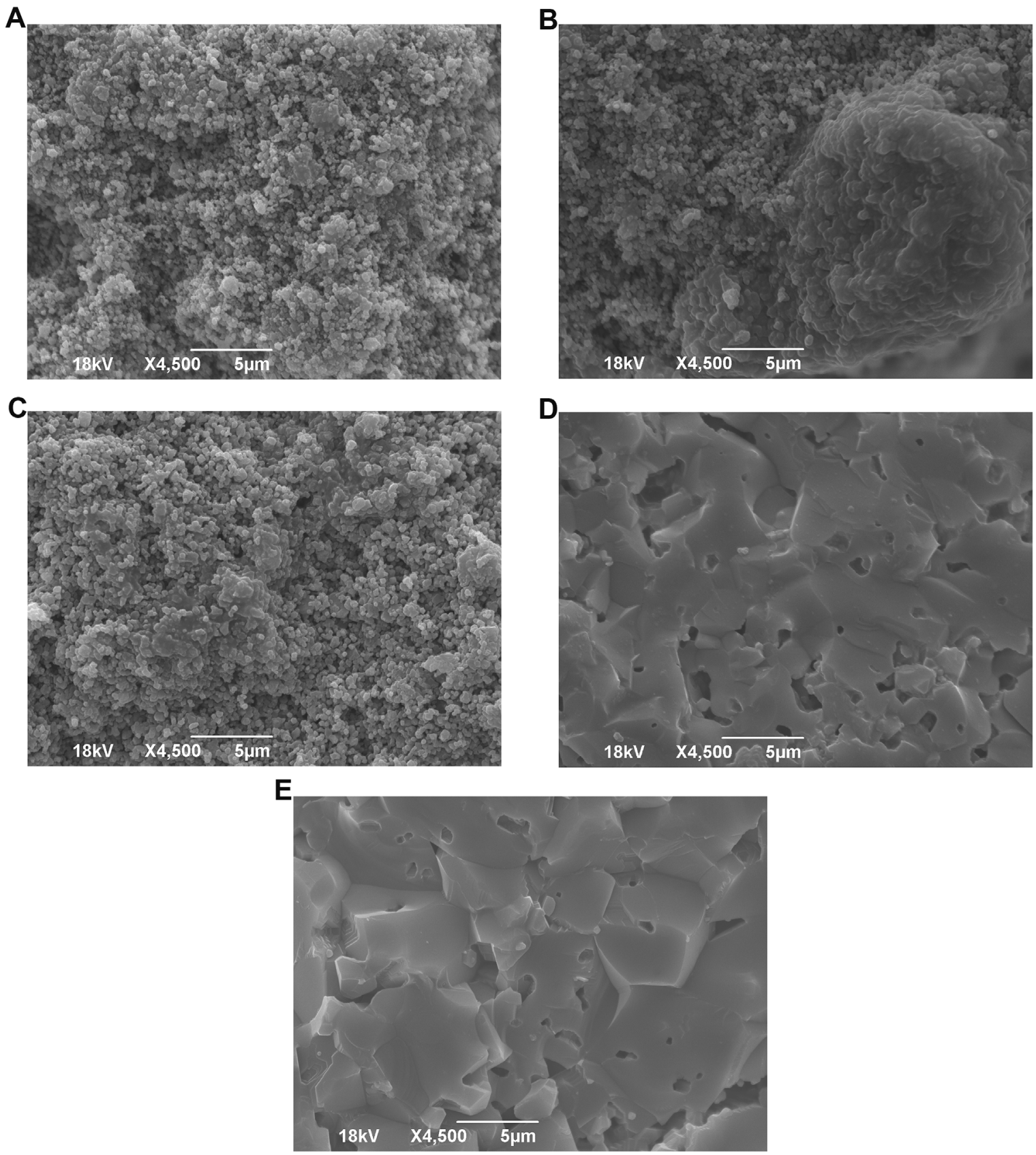

Fig. 7. SEM micrographs of fracture surfaces of sintered samples: a) AM-60-1200, b) AM-60-1300, c) AM-60-1400, d) AM-60-1500, and e) AM-60-1600.

changes in the microstructures. Combined, these observations suggest that higher density and more homogeneous microstructures were responsible for the higher values of dielectric permittivity as sintering temperatures increased. The relative permittivity for approximately $50 \%$ from values as low as $\sim 3.2$ for AM-0-1200 to almost 6 for AM-0-1600. For all specimens, the measured loss tangent was below the resolution of the measurement method, $(<0.002)$, indicating low dielectric losses.

The strength of the sintered specimens also increased as sintering temperature increased as summarized in Table 2 . The strength values were minimum for samples sintered at 1200 and $1300^{\circ} \mathrm{C}$. Increased sintering temperature led to an increase in strength. Specimens sintered at $1200^{\circ} \mathrm{C}$ had strengths of $\sim 10 \mathrm{MPa}$ or lower, which increased to strengths of more than $65 \mathrm{MPa}$ after sintering at $1600^{\circ} \mathrm{C}$. The maximum strength was obtained for AM-0-1600, which had the highest density, indicating that strength was strongly influenced by final density.

\section{Conclusions}

The influence of mechanical activation on synthesis and properties of spinel ceramics was investigated. $\mathrm{MgAl}_{2} \mathrm{O}_{4}$ ceramics were prepared by solid state reaction between $\mathrm{MgO}$ and $\alpha-\mathrm{Al}_{2} \mathrm{O}_{3}$ powders during conventional sintering process. Prior to heating, part of powder mixture was subjected to high energy planetary ball milling for $60 \mathrm{~min}$. The phase composition, microstructure, electrical and mechanical properties of the bulk materials were characterized systematically. The most important conclusions are:

(1) 60 min of high-energy ball milling lead to reduction of particle size and introduction of defects into the particles.

(2) $\mathrm{MgAl}_{2} \mathrm{O}_{4}$ spinel was formed by heating to temperatures low as $1200{ }^{\circ} \mathrm{C}$. For non-activated powders, spinel was the major phase, but traces of $\mathrm{MgO}$ were observed for reaction temperatures as high 


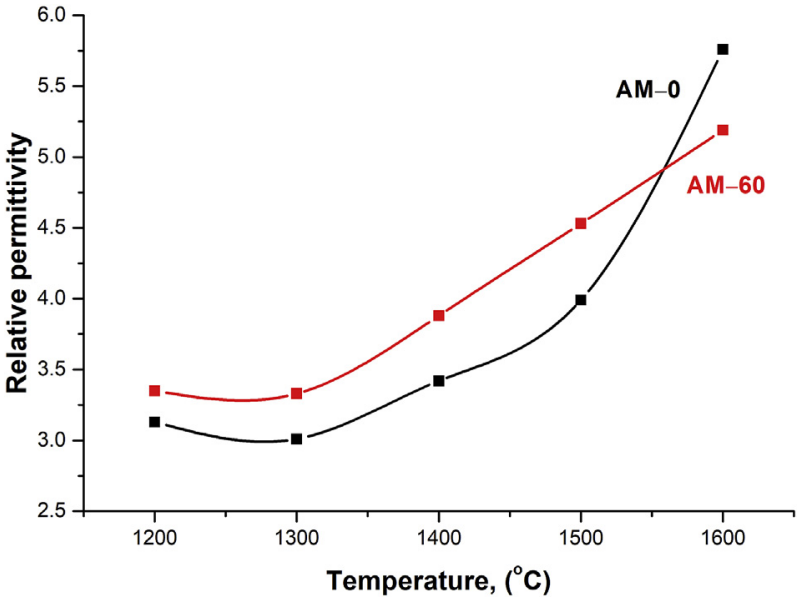

Fig. 8. Relative permittivity as a function of sintering temperature.

Table 2

Tensile strength, load at failure, and $k$ (thickness to diameter) ratio for all sintered samples.

\begin{tabular}{llll}
\hline Sample & $P(\mathrm{~N})$ & $k(\mathrm{~mm})$ & $\sigma_{\mathrm{t}}(\mathrm{MPa})$ \\
\hline AM-0-1200 & 258.24 & 0.2238 & 10.7 \\
AM-60-1200 & 170.28 & 0.2349 & 7.1 \\
AM-0-1300 & 144.17 & 0.2205 & 6.0 \\
AM-60-1300 & 321.64 & 0.2289 & 14.2 \\
AM-0-1400 & 240.04 & 0.2238 & 10.4 \\
AM-60-1400 & 270.76 & 0.2247 & 12.9 \\
AM-0-1500 & 946.73 & 0.2342 & 51.8 \\
AM-60-1500 & 399.14 & 0.2293 & 22.4 \\
AM-0-1600 & 1376.52 & 0.2248 & 83.5 \\
AM-60-1600 & 1149.66 & 0.2293 & 68.6 \\
\hline
\end{tabular}

as $1600{ }^{\circ} \mathrm{C}$. Single-phase spinel was obtained by heating mechanically activated powders to $1400^{\circ} \mathrm{C}$ or higher, indicating that the activated powders had higher reactivity.

(3) Analysis of microstructures showed that AM-0-1600 and AM-60-1600 had no open porosity, indicating that final stage sintering was reached. As porosity decreased strength increased with the highest strengths observed for specimens sintered at $1600{ }^{\circ} \mathrm{C}$, which were $\sim 84$ for $\mathrm{AM}-0-1600$ and $69 \mathrm{MPa}$ for AM-60-1600. As density increased, the pores became more regular in shape. Finally, increasing density also lead to increases in dielectric permittivity from lowest values of about 3 after sintering at $1200{ }^{\circ} \mathrm{C}$ to values of about 6 after sintering at $1600^{\circ} \mathrm{C}$.

\section{Acknowledgments}

This investigation was supported by the Serbian Ministry of Education, Science and Technological Development of the Republic of Serbia, and it was conducted under the following projects: OI 172057 , III 45007 and III 45019. The authors would like to thank Dr. Smilja Marković for PSA measurements and Dr. Miodrag Mitrić for XRD measurements.

\section{References}

[1] A. Zegadi, M. Kolli, M. Hamidouche, G. Fantozzi, Transparent $\mathrm{MgAl}_{2} \mathrm{O}_{4}$ spinel fabricated by spark plasma sintering from commercial powders, Ceram. Int. 44 (2018) 18828-18835.

[2] D. Han, J. Zhang, P. Liu, G. Li, S. Wang, Densification and microstructure evolution of reactively sintered transparent spinel ceramics, Ceram. Int. 44 (2018) $11101-11108$
[3] Z. Quan, Z. Wang, X. Wang, H. Liu, Y. Ma, Effect of $\mathrm{CeO}_{2}$ addition on the sintering behavior of pre-synthesized magnesium aluminate spinel ceramic powders, Ceram. Int. 45 (2019) 488-469.

[4] N. Obradović, S. Filipović, N. Đorđević, D. Kosanović, S. Marković, V. Pavlović, D. Olćan, A. Đorđević, M. Kachlik, K. Maca, Effects of mechanical activation and two-step sintering on the structure and electrical properties of cordierite-based ceramics, Ceram. Int. 42 (2016) 13909-13918.

[5] C.J. Ting, H.Y. Lu, Hot-pressing of magnesium aluminate spinel-II. Microstructure development, Acta Mater. 47 (1999) 831-840.

[6] C.J. Ting, H.Y. Lu, Hot-pressing of magnesium aluminate spinel-I. Kinetics and densification mechanism, Acta Mater. 47 (1999) 817-830.

[7] M.R. Merac, I.E. Reimanis, C. Smith, et al., Effect of impurities and LiF additive in hot-pressed transparent magnesium aluminate spinel, Int. J. Appl. Ceram. Technol. 10 (2013) 33-48.

[8] J.M. Kim, H.N. Kim, Y.J. Park, et al., Fabrication of transparent $\mathrm{MgAl}_{2} \mathrm{O}_{4}$ spinel through homogenous green compaction by microfluidization and slip casting, Ceram. Int. 41 (2015) 13354-13360.

[9] K. Morita, B.N. Kim, H. Yoshida, et al., Influence of spark plasma sintering (SPS) conditions on transmission of $\mathrm{MgAl}_{2} \mathrm{O}_{4}$ Spinel, J. Am. Ceram. Soc. 98 (2015) 378-385.

[10] K. Morita, B.N. Kim, H. Yoshida, et al., Assessment of carbon contamination in $\mathrm{MgAl}_{2} \mathrm{O}_{4}$ spinel during spark-plasma-sintering (SPS) processing, J. Ceram. Soc. Jpn. 123 (2015) 983-988.

[11] M. Sokol, S. Kalabukhov, M.P. Dariel, et al., High-pressure spark plasma sintering (SPS) of transparent polycrystalline magnesium aluminate spinel (PMAS), J. Eur. Ceram. Soc. 34 (2014) 4305-4310.

[12] R. Macaigne, S. Marinel, D. Goeuriot, S. Saunier, Sintering paths and mechanisms of pure $\mathrm{MgAl}_{2} \mathrm{O}_{4}$ conventionally and microwave sintered, Ceram. Int. 44 (2018) 21107-21113.

[13] A. Krell, K. Waetzig, J. Klimke, Influence of the structure of $\mathrm{MgO}^{\prime} \mathrm{nAl}_{2} \mathrm{O}_{3}$ spinel lattices on transparent ceramics processing and properties, J. Eur. Ceram. Soc. 32 (2012) 2887-2898

[14] L. Esposito, A. Piancastelli, P. Miceli, et al., A thermodynamic approach to obtaining transparent spinel $\left(\mathrm{MgAl}_{2} \mathrm{O}_{4}\right)$ by hot pressing, J. Eur. Ceram. Soc. 35 (2015) 651-661.

[15] M. Suarez, V. Rocha, A. Fernandez, et al., Synthesis and processing of spinel powders for transparent ceramics, Ceram. Int 40 (2014) 4065-4069.

[16] J. Rufner, D. Anderson, K. Benthem, et al., Synthesis and sintering behavior of ultrafine $(<10 \mathrm{~nm}$ ) magnesium aluminate spinel nanoparticles, J. Am. Ceram. Soc. 96 (2013) 2077-2085.

[17] S.S. Balabanov, R.P. Yavetskiy, A.V. Belyaev, et al., Fabrication of transparent $\mathrm{MgAl}_{2} \mathrm{O}_{4}$ ceramics by hot-pressing of sol-gel-derived nanopowders, Ceram. Int. 41 (2015) 13366-13371.

[18] S. Filipović, V.P. Pavlović, N. Obradović, V. Paunović, K. Maca, V.B. Pavlović, The impedance analysis of sintered $\mathrm{MgTiO}_{3}$ ceramics, J. of All. and Comp. 701 (2017) $107-115$

[19] N. Obradović, N. Đorđević, S. Filipović, S. Marković, D. Kosanović, M. Mitrić, V. Pavlović, Reaction kinetics of mechanically activated cordierite-based ceramics studied via DTA, J. Therm. Anal. Calorim, DOI 10.1007/s10973-015-5132-9.

[20] S. Filipović, N. Obradović, S. Marković, A. Đorđević, I. Balać, A. Dapčević, J. Rogan, V. Pavlović, Physical properties of sintered alumina doped with different oxides, Sci. Sinter. 50 (2018) 409-419.

[21] N. Obradović, V. Blagojević, S. Filipović, N. Đorđević, D. Kosanović, S. Marković, M. Kachlik, K. Maca, V. Pavlović, Kinetics of thermally activated processes in cordierite-based ceramics, J. Therm. Anal. Calorim. (2018), https://doi.org/10.1007/ s10973-018-7924-1.

[22] A. Peleš, N. Đorđević, N. Obradović, N. Tadić, V.B. Pavlović, Influence of prolonged sintering time on density and electrical properties of isothermally sintered cordierite-based ceramics, Sci. Sinter. 45 (2013) 157-164.

[23] S. Filipović, N. Obradović, V.B. Pavlović, M. Mitrić, A. Đorđević, M. Kachlik, K. Maca, Effect of consolidation parameters on structural, microstructural and electrical properties of magnesium titanate ceramics, Ceram. Int. 42 (2016) 9887-9898.

[24] F. Tavangarian, G. Li, Mechanical activation assisted synthesis of nanostructure $\mathrm{MgAl}_{2} \mathrm{O}_{4}$ from gibbsite and lansfordite, Powder Technol. 267 (2014) 333-338.

[25] F. Tavangarian, R. Emadi, Synthesis and characterization of pure nanocrystalline magnesium aluminate spinel powder, J. of All. and Comp. 489 (2010) 600-604.

[26] I. Ganesh, A review on magnesium aluminate $\left(\mathrm{MgAl}_{2} \mathrm{O}_{4}\right)$ spinel: synthesis, processing and applications, Int. Mater. Rev. 58 (2) (2013) 63-112, https://doi.org/10. 1179/1743280412Y.0000000001.

[27] W. Kraus, G. Nolze, PowderCell for Windows, V.2.4, Federal Institute for Materials Research and Testing, Berlin, Germany.

[28] R.G. Garwey, Powder Diffr. 1 (1986) 114.

[29] R.H. Marion, J.K. Johnstone, A parametric study of the diametral compressin test for ceramics, Am. Ceram. Soc. Bull. 56 (11) (1977) 998-1003.

[30] Y. Yu, J. Yin, Z. Zhong, Shape effects in the Brazilian tensile strength test and a 3D FEM correction, Int. J. Rock Mech. Min. Sci. 43 (4) (2006) 623-627.

[31] N. Obradović, S. Filipović, N. Đorđević, D. Kosanović, V. Pavlović, D. Olćan, A. Đorđević, M. Kachlik, K. Maca, Microstructural and electrical properties of cordierite-based ceramics obtained after two-step sintering technique, Sci. Sinter. 48 (2016) 157-165. 